\title{
Improved ELISA with immunoabsorbent-purified mycobacterial antigen for serodiagnosis of tuberculosis
}

\author{
P. THONGKRAJAI, V.LULITANON and C. CHAMNANVANAKIT*
}

Department of Microbiology, Faculty of Medicine, Khon Kaen University, Khon Kaen 40002, Thailand, and "Khon Kaen Second Zonal Tuberculosis Center, Department of Communicable Disease Control, Ministry of Public Health, Thailand

\begin{abstract}
Summary. An antigen was purified from Mycobacterium tuberculosis H37Ra culture filtrate by immunoabsorbent affinity chromatography with $\mathrm{CNBr}$-activated sepharose 4B column coupled with pooled $\gamma$-globulin fraction from patients with active tuberculosis. The column was washed extensively with PBS and eluted with $3 \mathrm{M}$ sodium thiocyanate. Peak fractions were pooled and used as coating antigen in an ELISA. Sera from 86 normal subjects and 54 patients with active tuberculosis were tested against the immunoabsorbed antigen by ELISA with biotin-conjugated antihuman globulin and avidin-peroxidase reagents. At a selected "cut-off" dilution of $320,49(91 \%)$ of 54 sera from active cases and $8(9 \cdot 3 \%)$ of 86 sera from normal subjects gave positive test results - a sensitivity and specificity each of $91 \%$, compared with our previous results of sensitivity $75 \%$ and specificity $83 \%$ with PPD as antigen.
\end{abstract}

\section{Introduction}

The conventional method for the diagnosis of tuberculosis by culture has several disadvantagesit is time consuming and the diagnostic test has low specificity and sensitivity. Therefore, a serological method, particularly one based on an ELISA system for the measurement of antibodies to mycobacterial antigens seemed to be an appropriate approach (Stroebel et al., 1982; Benjamin et al., 1984; Krambovitis, 1986). We have previously reported that anti-PPD antibodies, detected by ELISA, in patients with active and inactive tuberculosis correlated well with the presence and absence of the disease (Thongkrajai and Chamnanvanakit, 1986). Although the reported results were promising, significantly high levels of antibodies to PPD were detected in several normal serum samples and the specificity and sensitivity of the test were not satisfactory. Several authors have used more purified fractions of mycobacterial antigens in ELISA (Reggiardo et al., 1980; Stroebel et al., 1982; Daniel et al., 1985; Affronti et al., 1986; Chawla et al., 1986); the purified fractions gave different degrees of specificity and sensitivity. So far, no purified fraction of mycobacterial antigens has been found to be an appropriate antigen in an ELISA system for the serodiagnosis of tuberculosis. In the present

Received 11 May 1988; accepted 9 Jan. 1989. report we describe the purification of mycobacterial antigens and their use for detecting specific antimycobacterial antibodies in sera from patients with active tuberculosis.

\section{Materials and methods}

Sera

Sera used in this study were the same collection of samples used in our previous study (Thongkrajai and Chamnanvanakit, 1986). They were stored with an equal volume of glycerol at $-70^{\circ} \mathrm{C}$. Six groups of sera were tested:

(i) 54 sera from patients with active pulmonary tuberculosis, i.e., acid-fast bacilli were detected in sputum by light microscopy and Mycobacterium tuberculosis was isolated and identified according to the method of Vestal (1975). Patients had received chemotherapy for less than one year.

(ii) 27 sera from patients with inactive pulmonary tuberculosis, i.e., patients who had been active cases but had been treated regularly for more than 18 months; mycobacteria had not been found in their sputum for at least one year. Their clinical and radiological signs showed no reactivation.

(iii) 86 normal sera from a community health study collection of 400 sera from healthy individuals who had no clinical or radiological signs of pulmonary tuberculosis.

(iv) 23 VDRL-positive sera and (v) 30 sera with rheumatoid factor (RF) from the serodiagnostic unit of Srinagarind Hospital, Faculty of Medicine, Khon Kaen University. 
(vi) seven malarial sera from the Malaria Research Project, Department of Parasitology, Faculty of Medicine, Khon Kaen University.

\section{Antigen}

Culture filtrate (CF) of $M$. tuberculosis strain H37Ra was prepared according to the method of Daniel and Ferguson (1970), lyophilised and stored at $4^{\circ} \mathrm{C}$. The purified mycobacterial antigen (PMA) was prepared from the CF by immunoabsorbent affinity chromatography with human immune serum globulins. The human immune serum was a pooled serum from 20 patients with active pulmonary tuberculosis. The globulin fraction was prepared by precipitation with $33 \%$ ammonium sulphate, three times at $4{ }^{\circ} \mathrm{C}$ and was coupled to $\mathrm{CNBr}$-activated sepharose 4B (Pharmacia) at a ratio of $3 \mathrm{mg}$ of protein/ $\mathrm{ml}$ of gel. The method of preparation of PMA, by use of the immunosorbent column, was similar to that described by Daniel and Anderson (1977), with the modification that elution was with $3 \mathrm{M}$ sodium thiocyanate. Eluates were pooled and dialysed extensively against distilled water. The pooled eluate was concentrated by lyophilisation and stored at $4^{\circ} \mathrm{C}$, its protein content was determined by the method of Lowry et al. (1951).

\section{ELISA}

Flat-bottom polystyrene microtitration plates (NUNC) were coated with $100-\mu \mathrm{l}$ volumes of PMA, at a concentration of $0.2 \mathrm{mg} / 100 \mathrm{ml}$, at $37^{\circ} \mathrm{C}$ for $1 \mathrm{~h}$. Sera were diluted in diluting buffer-phosphate buffered saline (PBS, pH 7.4) containing $0.35 \mathrm{M} \mathrm{NaCl}$, Tween $200.1 \%$ and milk powder $1 \%$-in two-fold serial dilutions from 40 to 5120 and $100 \mu \mathrm{l}$ of each dilution was added to the antigen-coated microtitration plates and incubated at $37^{\circ} \mathrm{C}$ for $1 \mathrm{~h}$. After washing, biotin-conjugated antihuman IgG (Calbiochem) and avidin-peroxidase (Calbiochem) were added and incubated at $37^{\circ} \mathrm{C}$ for $1 \mathrm{~h}$. All assays were performed in duplicate. To assess intra- and inter-assay variation, reference positive and negative sera were tested concomitantly in every microtitration plate of all experiments. The optical density at $492 \mathrm{~nm}$ $\left(\mathrm{OD}_{492}\right)$ values were measured in an ELISA reader (Dynatech). $\mathrm{OD}_{492}$ values of $0 \cdot 1$ or less were regarded as negative results.

\section{Results}

The antibody titres of test sera are shown in table I. The geometric mean titres of sera from patients with active tuberculosis and normal subjects were 758.6 and 96.2 with PMA and 1478 and 161.8 with crude CF antigens, respectively. The day-to-day variations (inter-assay) were 11.3 and 12.6 with PMA and CF antigens respectively; the intra-assay variations were $<10 \%$.
Table I. Titres of antibodies against PMA and crude CF of mycobacteria in patients with active pulmonary tuberculosis (TB) and normal subjects

\begin{tabular}{|c|c|c|c|c|}
\hline \multirow[b]{3}{*}{ Antibody titre } & \multicolumn{4}{|c|}{$\begin{array}{c}\text { Number of samples that gave the indicated } \\
\text { titre in ELISA with }\end{array}$} \\
\hline & \multicolumn{2}{|c|}{ PMA } & \multicolumn{2}{|c|}{$\mathrm{CF}$} \\
\hline & TB & Normal & TB & Normal \\
\hline$<40$ & 0 & 11 & 0 & 0 \\
\hline 40 & 0 & 20 & 0 & 12 \\
\hline 80 & 2 & 24 & 1 & 16 \\
\hline 160 & 3 & 23 & 4 & 5 \\
\hline 320 & 12 & 8 & 2 & 18 \\
\hline 640 & 11 & 0 & 9 & 7 \\
\hline 1280 & 17 & 0 & 10 & 3 \\
\hline 2560 & 4 & 0 & 14 & 0 \\
\hline 5120 & 4 & 0 & 13 & 0 \\
\hline$>5120$ & 1 & 0 & 0 & 0 \\
\hline Total & 54 & 86 & 53 & 61 \\
\hline Geometric mean & $758 \cdot 61$ & $96 \cdot 24$ & $1478 \cdot 00$ & $161 \cdot 82$ \\
\hline
\end{tabular}

Receiver operating characteristic (ROC) curves are shown in fig. 1. The curves are based on results shown in table I. It can be seen that for various levels of sensitivity of the test, the tests with PMA gave better specificity (low false positive rate) than tests with crude $\mathrm{CF}$ antigens. The ROC curves indicated that the test yielded the highest sensitivity with the smallest fraction of false positive results when an antibody titre of $\geqslant 320$ was taken to be a positive result. Therefore, the following analyses were based on the assumption that the test was positive (i.e., the serum contained a significant

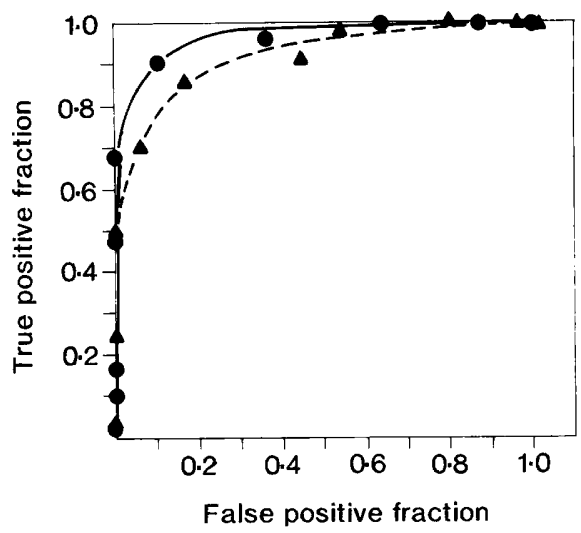

Fig. 1. Receiver operating characteristic (ROC) curves for ELISA with PMA ( $)$ and CF ( $\mathbf{\Delta})$ to detect anti-mycobacterial antibodies ( $\mathrm{IgG})$. The true positive fraction (sensitivity) was plotted against the false positive fraction ( $1-$ specificity) for each antigen at each dilution tested from 40 to 5120 . 
level of antibodies to $M$. tuberculosis) when the titre was $\geqslant 320$.

The $2 \times 2$ contingency table for the analysis of sensitivity and specificity of the test is represented by table II. The sensitivity of the test was similar with either PMA or crude CF antigens $(90.7 \%$, $90.6 \%$ ), but the specificity was much greater with PMA $(90.7 \%)$ than with CF $(54.1 \%)$. The positive and negative predictive values of the PMA-ELISA were 0.86 and 0.94 , whereas those of the CF-ELISA were 0.63 and 0.87 respectively.

Fig. 2 shows the PMA-ELISA results obtained with sera from four groups of subjects, the VDRLand RF-positive groups, and patients with malaria or inactive tuberculosis. With a significant titre considered to be $\geqslant 320$, sera from $26 \%$ (6 of 23 ) of VDRL-positive, $23 \%$ (7 of 30) RF-positive, $29 \%$ (2 of 7) malarial and $59 \%$ (16 of 27) inactive tuberculosis patients gave positive results.

\section{Discussion}

In our previous serodiagnostic study in which PPD was used in an ELISA to measure anti-PPD antibodies in the serum of patients with tuberculosis, we found that PPD cross-reacted with $16.9 \%$ of normal sera (Thongkrajai and Chamnanvanakit, 1986). This might have been because PPD contains many antigenic determinants. In the present study, we attempted to purify mycobacterial antigens from $M$. tuberculosis $\mathrm{H} 37 \mathrm{Ra}$ by immunoabsorbent affinity chromatography with human immunoglobulins against tuberculosis coupled to sepharose 4B, enabling the mycobacterial antigens to be absorbed and then eluted from the column. The purified mycobacterial antigen reacted with a smaller number $(9.3 \%)$ of normal serum samples than when non-purified CF antigen was used $(46 \%)$. The

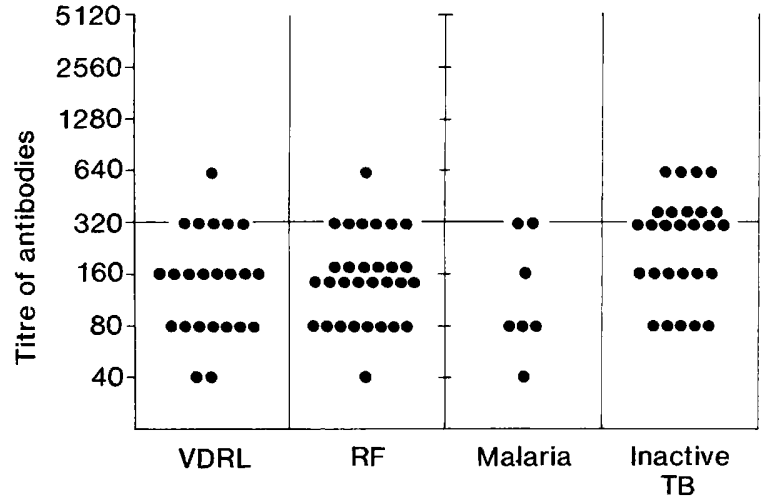

Fig. 2. The activity of antibodies (IgG) against PMA in VDRLand RF-positive sera and in sera from patients with malaria or inactive pulmonary tuberculosis. An antibody titre $\geqslant 320$ was considered to be a significant titre for the serodiagnosis of pulmonary tuberculosis.

biotin-avidin complex was used in this test to increase the sensitivity of the test. We believe that we have produced an improved ELISA for use as a serodiagnostic test for tuberculosis.

Because of our experience with ELISA that reliance on working dilutions $<200$ should be avoided, because of the interference of highly concentrated normal gamma globulins, we selected a titre of $\geqslant 320$ as a cut off point. If this is considered to be a significant titre (i.e., a positive test), 49 $(91 \%)$ of 54 and $8(9.3 \%)$ of 86 serum samples from patients and normal subjects, respectively, gave positive results. This represents a sensitivity and specificity each of $91 \%$ with PMA. The positive and negative predictive values were 0.86 and 0.94 respectively. When the non-purified $C F$ antigen was used in the ELISA test, similar sensitivity $(91 \%)$ was observed but the specificity was markedly reduced $(54 \%)$. In a previous report, Nassau et al.

Table II. Specificity and sensitivity of ELISA with PMA and CF antigens for serodiagnosis of pulmonary tuberculosis

\begin{tabular}{|c|c|c|c|c|c|c|}
\hline \multirow{3}{*}{$\begin{array}{l}\text { ELISA test } \\
\text { result* }\end{array}$} & \multicolumn{6}{|c|}{ Number $(\%)$ of samples that gave the indicated result in ELISA with } \\
\hline & \multicolumn{3}{|c|}{ PMA } & \multicolumn{3}{|c|}{$\mathrm{CF}$} \\
\hline & TB & Normal & Total & $\mathrm{TB}$ & Normal & Total \\
\hline Positive & $\begin{array}{c}49 \\
(90 \cdot 7)\end{array}$ & $\begin{array}{c}8 \\
(9 \cdot 3)\end{array}$ & 57 & $\begin{array}{l}48 \\
(90 \cdot 6)\end{array}$ & $\begin{array}{c}28 \\
(45 \cdot 9)\end{array}$ & 76 \\
\hline Negative & $\begin{array}{c}5 \\
(9 \cdot 3)\end{array}$ & $\begin{array}{c}78 \\
(90 \cdot 7)\end{array}$ & 83 & $\begin{array}{c}5 \\
(9 \cdot 4)\end{array}$ & $\begin{array}{c}33 \\
(54 \cdot 1)\end{array}$ & 38 \\
\hline Total & 54 & 86 & & 53 & 61 & \\
\hline
\end{tabular}

*Antibody titre $\geqslant 320$ was considered to be a positive result. 
(1976) demonstrated $61 \%$ sensitivity and $96 \%$ specificity with a similar culture filtrate of $M$. tuberculosis. In the present study, the purified antigen from $M$. tuberculosis was superior to the crude culture filtrate antigen for use in an ELISA serodiagnostic test for tuberculosis. Benjamin et al. (1984) also reported that purified antigens were superior to a culture filtrate of $M$. tuberculosis.

It has been reported that low titres of antibodies to mycobacterial antigens may be associated with a heavy infection, and that antigens may be released into the blood circulation and cause the temporary suppression of antibody formation (Krambovitis, 1986; Krambovitis et al., 1986). Suspected cases of tuberculosis who have low antibody titres should, therefore, be followed up and, if possible, examined for circulating mycobacterial antigens. Some sera

\section{REFERENCES}

Affronti L F, Taylor R, Hassan E M 1986 Comparison between tuberculo-proteins $\mathrm{A}$ and $\mathrm{C}$ in the serodiagnosis of tuberculosis by enzyme-linked immunosorbent assay. International Archives of Allergy and Applied Immunology 80: 8184.

Benjamin R G, Debanne S M, Ma Y, Daniel T M 1984 Evaluation of mycobacterial antigen in an enzyme-linked immunosorbent assay (ELISA) for the serodiagnosis of tuberculosis. Journal of Medical Microbiology 18: 309-318.

Chawla T C, Sharma A, Kiran U, Bhargava D K, Tandon B N 1986 Serodiagnosis of intestinal tuberculosis by enzyme immunoassay and soluble antigen fluorescent antibody tests using a saline extracted antigen. Tubercle 67: 55-60.

Daniel T M, Anderson P A 1977 The use of immunosorbents for the purification of mycobacterial antigens. Journal of Laboratory and Clinical Medicine 90: 354-360.

Daniel T M, Benjamin R G, Debanne S M, Ma Y, Balestrino E A 1985 ELISA of IgG antibody to $M$. tuberculosis antigen 5 for serodiagnosis of tuberculosis. Indian Journal of Pediatrics 52: 349-355.

Daniel T M, Ferguson L E 1970 The purification and characterization of two proteins from culture filtrates of Mycobacterium tuberculosis, H37Ra strain. Infection and Immunity 1 : $164-168$.

Krambovitis E 1986 Detection of antibodies to Mycobacterium tuberculosis plasma membrane antigen by enzyme-linked from normal subjects $(9 \cdot 3 \%)$ gave positive results, probably because they were from an area where many types of mycobacterial infection are endemic and $B C G$ vaccination is widespread. Unlike the sera from normal subjects, sera from other patients, i.e., VDRL- and RF-positive sera, malarial and inactive tuberculosis sera, gave a high proportion of positive results with PMA-ELISA. Thus, further studies are needed to test the assay with a greater variety of serum specimens, in particular sera from patients infected with other Mycobacterium spp.

This work was financially supported by the National Research Council of Thailand. We are grateful to all workers in the Malarial Research Project, Department of Parasitology, Faculty of Medicine, Khon Kaen University and to the staff of The Second Zonal Tuberculosis Center, Khon Kaen.

immunosorbent assay. Journal of Medical Microbiology 21 : 257-264.

Krambovitis E, Harris M, Hughes D T D 1986 Improved serodiagnosis of tuberculosis using two assay test. Journal of Clinical Pathology 39 : 779-785.

Lowry O H, Rosebrough N J, Farr A L, Randall R J 1951 Protein measurement with the folin phenol reagent. Journal of Biological Chemistry 193 : 265-275.

Nassau E, Parsons E R, Johnson G D 1976 The detection of antibodies to Mycobacterium tuberculosis by microplate enzyme-linked immunosorbent assay (ELISA). Tubercle 57 : $67-70$

Reggiardo Z, Vazquez E, Schnaper L 1980 ELISA test for antibodies against mycobacterial glycolipids. Journal of Immunological Methods 34: 55-60.

Stroebel A B, Daniel T M, Lau J H K, Leong J C Y, Richardson $\mathrm{H} 1982$ Serologic diagnosis of bone and joint tuberculosis by an enzyme-linked immunosorbent assay. Journal of Infectious Diseases 146: 280-283.

Thongkrajai P, Chamnanvanakit C 1986 An assessment of the enzyme-linked immunosorbent assay (ELISA) for diagnosis of pulmonary tuberculosis. Journal of the Medical Association of Thailand 69: 324-329.

Vestal A L (ed) 1975 Procedures for the isolation and identification of mycobacteria. Department of Health, Education and Welfare, Center for Disease Control, Atlanta, GA 